\title{
A Comparison of the Characteristics of Maternal Near-Misses and Maternal Deaths in Enugu, Southeast Nigeria: A 3-Year Prospective Study
}

This article was published in the following Dove Press journal: International Journal of Women's Health

\author{
George O Ugwu \\ Chukwuemeka A lyoke (D) \\ Euzebus C Ezugwu \\ Leonard O Ajah (I) \\ Hyacinth E Onah \\ Benjamin C Ozumba \\ Department of Obstetrics and \\ Gynaecology, College of Medicine, \\ University of Nigeria, Nsukka, Nigeria
}

Correspondence: George O Ugwu Tel +234803565 3435

Email ugwugeo@yahoo.com
Background: Maternal near-misses, also known as severe acute maternal morbidity, have become globally recognized as an appropriate indicator of obstetric care. Women experiencing maternal near-misses are more in number than maternal deaths, and can provide more specific and detailed evidence, as the patient herself can be a leading source of useful information.

Objective: To determine the frequency of maternal near-misses and maternal deaths in the University of Nigeria Teaching Hospital in Ituku-Ozalla, Enugu, document the primary determinant factor that caused these, and compare cases of maternal near-miss and maternal deaths. Methods: This was a 3-year prospective study of all women admitted for delivery or within 42 days of delivery or termination of pregnancy at the hospital. Data were collected prospectively in consecutive patients in a pro forma manner and entered into SPSS version 17 for Windows.

Results: There was a total of 2,236 deliveries, of which 88 had severe maternal outcomes. Of the latter, 60 were maternal near-misses, while 28 suffered maternal death. The maternal nearmiss:mortality ratio was found to be 2.14 . The maternal mortality ratio here was 1,252 per 100,000. All the 88 women that had severe maternal outcomes lived at least $5 \mathrm{~km}$ from the hospital. The leading organ-system dysfunction in this study was cardiovascular, manifesting as shock and cardiac arrest, and respiratory, manifesting as gasping and cyanosis. Leading complications were severe hemorrhage, anemia, and hypertensive disorders. The pattern of complications was similar in both near-misses and maternal deaths, but cases of hypertensive disorders and exploratory laparotomy as an intervention for those with organ dysfunction were noted to be higher in near-miss cases, and differences were statistically significant.

Conclusion: It was concluded that despite numerous similarities in the characteristics of patients who had had maternal near-misses or died, our study points out that those who succumb to death are often $<40$ years of age, poorly educated, unemployed, usually present as unbooked emergencies from a distance $>5 \mathrm{~km}$ and suffer maternal death within 24 hours of presentation.

Keywords: maternal near-miss, maternal deaths, Enugu, Nigeria

\section{Introduction}

Maternal near-misses (MNMs), also known as severe acute maternal morbidity, have gained global recognition as an appropriate indicator of maternal care and services. ${ }^{1}$ The World Health Organization (WHO) has defined an MNM as a woman who nearly died but survived a complication that occurs at pregnancy, childbirth, or within 42 days after termination of pregnancy. ${ }^{1,2}$ Cases of MNMs are more common than maternal death and usually provide specific and detailed evidence, with the patient becoming a leading source of useful information. Maternal mortality in our environment is mostly a result of known and treatable 
complications of pregnancy and childbirth, and the study of MNMs can provide additional insights into the pathways of occurrence of such preventable deaths. ${ }^{3,4}$

It was previously assumed that maternal death records in hospitals were just a tiny part of what happens in the community, due to unsupervised deliveries in traditional settings and homes, but emerging evidence clearly suggests the occurrence of many deaths within hospitals, including tertiary centers. ${ }^{3,5-7}$ This is partly due to late referral of severely ill obstetric patients from private hospitals, traditional birth attendants' homes, and spiritual houses. ${ }^{3,5}$ Therefore, a reduction in absolute numbers of maternal deaths in tertiary centers can be a major step toward achieving an appreciable reduction in maternal deaths in our environment.

The situation of maternal mortality in our country has often been described as unacceptable, as there is high maternal mortality and morbidity in the face of inadequacies in maternal health services. The leading causes of maternal death include obstetric hemorrhage, obstructed labor, eclampsia, and sepsis. The need to improve health services and provide skilled birth attendants at delivery will help to reduce high maternal deaths.

The accuracy of maternal mortality figures in our country has remained a subject of controversy, and most figures are based on poorly conducted retrospective studies or estimates. In recent years, the use of MNM studies to evaluate institutions and health systems in providing adequate maternal healthcare has become increasingly popular and more reliable. To the best of our knowledge there has not been such study in the southeast of Nigeria. Similar studies have mostly been retrospective or prospective for a few months. In view of the wide regional variation in maternal mortality figures in Nigeria, it remains pertinent to clarify all possible details regarding MNMs in each region.We therefore undertook a 3-year prospective study to determine the frequency of MNMs and maternal deaths in the University of Nigeria Teaching Hospital (UNTH) Enugu, document the primary determining factor that caused them, and compare cases of MNMs and maternal deaths.

\section{Methods}

The study was carried out in the Obstetrics and Gynaecology Unit of UNTH, Ituku-Ozalla, Enugu, southeast Nigeria. All women admitted for delivery, within 42 days of delivery, or termination of pregnancy during the 36month study period constituted the study population. All women who met WHO criteria for maternal deaths and
MNMs, irrespective of booking status or place of antenatal care, were included. Women brought in dead to the hospital were not included.

This was a prospective study, and was approved by the hospital ethics committee . Data were gathered continuously from April 1, 2013 to March 312016 in a pro forma manner. Information sought included maternal sociodemographic characteristics, obstetric history, organ-system dysfunction leading to MNMs or death, primary determining factor for MNMs or death, and contributory health-service events.

Data collection was carried out by trained research assistants: four resident doctors from the Internal Medicine Department who understood the dynamics of maternal care in order to extract relevant information, but were not directly involved in providing maternal care. This approach was adopted to eliminate bias in data collection. Data were collected continuously in a prospective manner until hospital discharge or death occurred. Data were entered into SPSS version 17 for Windows and analyzed using inferential statistics at a $95 \%$ level of confidence. Socodemographic and other maternal characteristics were identified and compared between those who experienced MNMs and maternal deaths. The outcome variable were maternal death or MNMs.

MNMs were defined using different criteria. There were three major approaches to the identification of MNM cases: clinical criteria related to a specific disease entity (preeclampsia, postpartum hemorrhage), management-based criteria (admission to intensive care, need for a blood transfusion), or organ-system dysfunction-based criteria. ${ }^{5,6}$ Depending on these different approaches, the prevalence of MNMs varies. The MNM concept has helped in overcoming these challenges, and the WHO has adopted this as a tool in the assessment of quality of obstetric care. However, in 2009 a WHO working group for maternal mortality and morbidity classifications developed a consensus on MNM identification. This is based on two components: identification of potentially lifethreatening conditions, which may or may not be MNM cases (specific complications, such as severe preeclampsia and/or critical interventions, such as blood transfusion) and identification of MNM cases based on organ-system dysfunction and organ-dysfunction proxies, including clinical, laboratory, and management criteria.

\section{Ethics}

All participants provided written informed consent, and this study was conducted in accordance with the Declaration of Helsinki. 


\section{Results}

During the study period, there was total of 2,236 deliveries, of which 88 had severe maternal outcomes (SMOs). Of the latter, 60 were MNMs, while 28 were maternal deaths. The MNM:mortality ratio was found to be 2.14 , and that mortality index was calculated to be $31.8 \%$. The maternal mortality ratio here was 1,252 per 100,000. All 88 women that had SMOs were married, Christians. and lived at least $5 \mathrm{~km}$ from the hospital. Other sociodemographic characteristics are outlined in Table 1.

The leading organ-system dysfunction in this study was cardiovascular, manifesting as shock and cardiac arrest, and respiratory dysfunction, manifesting as gasping and cyanosis. Others are listed in Table 2. There were many complications encountered in the two groups during pregnancy (Table 3). The leading ones were severe hemorrhage, anemia, and hypertensive disorders. The pattern was similar in both MNMs and maternal deaths, but cases of hypertensive disorders and exploratory laparotomy were noted to be higher in MNMs, and the difference was statistically significant.

\section{Discussion}

Aajority of the women with SMOs had at least secondary education: $70 \%$ of those with MNMs and $85 \%$ of those who experienced maternal deaths. It was also found that $>95 \%$ were of low or middle socioeconomic status. This suggests that being educated and alone without a job or social support may not be enough to limit SMOs in our environment, where the economy is constrained. The absence of a reliable health-insurance scheme may be a contributing factor in this regard.

It is striking to note that all the women who experienced maternal deaths were admitted as unbooked emergencies. While $93 \%$ of MNMs were admitted as emergencies, $80 \%$ were unbooked. About $60 \%$ of all women with SMOs were admitted at night. Cases of unbooked emergencies admitted at night are likely to have worse outcomes, because of the likely absence of senior obstetricians and lack of optimal support services, including laboratory, theater, and anesthetic services.

In terms of age, it was found that all women who suffered maternal death were aged $<40$ years while $>15 \%$ of MNMs were aged $>40$ years. This underscores the fact that most deaths in this series were likely to have been preventable, and hence occurring even in younger women. A total of 24 of 28 women $(86 \%)$ who experienced maternal deaths had
Table I Maternal Characteristics, $n=88$

\begin{tabular}{|c|c|c|c|}
\hline & $\begin{array}{l}\text { Maternal } \\
\text { Near-Misses, } \\
n=60\end{array}$ & $\begin{array}{l}\text { Maternal } \\
\text { Deaths, } \\
\mathrm{n}=\mathbf{2 8}\end{array}$ & $\chi^{2}$ \\
\hline \multicolumn{4}{|l|}{ Age, years } \\
\hline$<40$ & 52 & 28 & 0.063 \\
\hline$\geq 40$ & 8 & 0 & \\
\hline \multicolumn{4}{|l|}{ Education } \\
\hline None & 4 & 0 & 0.001 \\
\hline Primary school & 12 & 4 & \\
\hline Secondary school & 16 & 20 & \\
\hline Postsecondary & 28 & 4 & \\
\hline \multicolumn{4}{|l|}{ Occupation } \\
\hline Unemployed & 8 & 8 & 0.96 \\
\hline Unskilled & 24 & 12 & \\
\hline Semiskilled & 20 & 8 & \\
\hline Skilled professional & 8 & 0 & \\
\hline \multicolumn{4}{|l|}{ Social class } \\
\hline Low & 20 & 16 & 0.063 \\
\hline Middle & 36 & 12 & \\
\hline High & 4 & 0 & \\
\hline \multicolumn{4}{|l|}{$\begin{array}{l}\text { Duration of hospital } \\
\text { admission }\end{array}$} \\
\hline $0-24$ hours & 0 & 16 & 0.060 \\
\hline 3-7 days & 16 & 4 & \\
\hline 8-4 days & 40 & 8 & \\
\hline$>42$ days & 4 & 0 & \\
\hline \multicolumn{4}{|l|}{ Mode of admission } \\
\hline Emergency & 56 & 28 & 0.162 \\
\hline Regular & 4 & 0 & \\
\hline \multicolumn{4}{|l|}{ Time of admission } \\
\hline $8: 00 \mathrm{am}-6: 00 \mathrm{pm}$ & 24 & 12 & 0.800 \\
\hline 6:01 pm-7:59 am & 36 & 16 & \\
\hline \multicolumn{4}{|l|}{ Referral status } \\
\hline Not referred & 20 & 8 & 0.825 \\
\hline Referred before labor & 12 & 8 & \\
\hline Referred during labor & 20 & 8 & \\
\hline Referred postpartum & 8 & 4 & \\
\hline \multicolumn{4}{|l|}{ Booking status } \\
\hline Booked & 12 & 0 & 0.011 \\
\hline Unbooked & 48 & 28 & \\
\hline
\end{tabular}

relatively low levels of education, stopping at primary or secondary school level, while only about half the women who had MNMs had such levels of education. As such, in relative terms, educational levels were lower among the majority of those that eventually died.

The women who experienced maternal deaths were also the ones that had shorter duration of hospital stay 
Table 2 Organ-System Dysfunction in Women with Severe Maternal Outcomes

\begin{tabular}{|c|c|c|c|}
\hline & $\begin{array}{l}\text { Near-Misses } \\
n=60\end{array}$ & $\begin{array}{l}\text { Maternal } \\
\text { Deaths, } \\
n=28\end{array}$ & $\chi^{2}$ \\
\hline \multicolumn{4}{|l|}{ Cardiovascular } \\
\hline Shock & 40 & 8 & 0.001 \\
\hline Cardiac arrest & 0 & 12 & 0 \\
\hline $\begin{array}{l}\text { Use of continuous vasoactive } \\
\text { drugs }\end{array}$ & 0 & 4 & 0.009 \\
\hline Cardiopulmonary resuscitation & 16 & 8 & 0.522 \\
\hline \multicolumn{4}{|l|}{ Respiratory } \\
\hline Acute cyanosis & 0 & 4 & 0.009 \\
\hline Gasping & 4 & 12 & 0 \\
\hline Identified renal dysfunction & & & \\
\hline $\begin{array}{l}\text { Oliguria unresponsive to } \\
\text { diuretics }\end{array}$ & 4 & 0 & 0.209 \\
\hline Dialysis for acute renal failure & 3 & 0 & 0 \\
\hline \multicolumn{4}{|l|}{ Coagulative } \\
\hline Failure to form clots & 8 & 0 & 0.040 \\
\hline Severe acute thromboembolism & 4 & 0 & 0.209 \\
\hline $\begin{array}{l}\text { Massive loss of blood or red } \\
\text { cells }\end{array}$ & 12 & 4 & 0.371 \\
\hline \multicolumn{4}{|l|}{ Hepatic } \\
\hline Jaundice (in preeclampsia) & 4 & 0 & 0.218 \\
\hline Global paralysis & 4 & 0 & 0.209 \\
\hline \multicolumn{4}{|l|}{ Uterine } \\
\hline $\begin{array}{l}\text { Hysterectomy due to uterine } \\
\text { infection }\end{array}$ & 8 & 8 & 0.572 \\
\hline
\end{tabular}

Table 3 Complications in Women with Severe Maternal Outcomes

\begin{tabular}{|l|l|l|l|}
\hline During Hospital Stay & $\begin{array}{l}\text { Near-Misses } \\
\mathbf{n = 6 0}\end{array}$ & $\begin{array}{l}\text { Maternal } \\
\text { Deaths, } \mathbf{n = 2 8}\end{array}$ & $\chi^{\mathbf{2}}$ \\
\hline Severe hemorrhage & 48 & 12 & 0.001 \\
Hypertensive disorder & 36 & 16 & 0.489 \\
Dystocia & 8 & 4 & 0.572 \\
Infection & 16 & 8 & 0.522 \\
Anemia & 36 & 16 & 0.489 \\
Admission to ICU & 12 & 8 & 0.264 \\
Emergency laparotomy & 20 & 8 & 0.011 \\
Transfusion of blood & 36 & 16 & 0.489 \\
\hline
\end{tabular}

than cases of MNMs. Almost all of them died within 24 hours of admission, indicating a consistent pattern of very ill and unbooked emergencies. However, there was no significant difference in terms of occupation and social class in the two groups in this study.

About $4 \%$ of all the women who had deliveries during the study period had SMOs, and this included both MNMs and maternal deaths. This percentage is much lower than the $17 \%$ recorded in a similar study in Sagamu, Nigeria. The low incidence may be due to the location of the permanent site of UNTH at Ituku-Ozalla, which is about $21 \mathrm{~km}$ from Enugu city. This distance may cause people who are critically ill to visit alternative hospitals within Enugu and equally delay their timely arrival to hospital for appropriate treatment.

However, the incidence ratio of MNMs of 26.8 per 1000 births recorded in this study is higher than the 19.8 per 1000 live birth in south Nigeria ${ }^{8}$ and 16 per 1,000 live births recorded as the Nigeria average. ${ }^{9}$ This incidence ratio is however comparable to the 28.6 per 1,000 live births in Accra, Ghana. ${ }^{10}$ The figures from this study put the maternal mortality ratio at 1,252 per 100,000 births, which is nearly double the widely quoted Nigeria figure of 814 per100,000 by the Ministry of Health. More recent estimates are even quoting a figure of 560 per $100,000 .{ }^{11}$ These wide variations in figures suggest data weakness, which makes important comparison and monitoring of trends difficult, especially at the global level. ${ }^{12-15}$ A recent study in south Nigeria got a higher maternal mortality of 1,908 per $100,0000^{8,11}$

Despite the low proportion of women who had SMOs, it is noteworthy that both the maternal mortality ratio and MNMincidence ratio were notably higher than previously recorded. This may have been due to the location of the hospital, late presentation of very ill patients, and inability of most private hospitals tohandle critically ill patients adequately. The obstetric unit may need a separate and dedicated intensive care unit, blood bank, and staff quarters for at least some obstetricians within the hospital, in order to improve MOs.

The leading organ dysfunction identified was cardiovascular which occurred in the form of shock and cardiac arrest, and respiratory dysfunction (gasping and acute cyanosis). Others included jaundice, coagulative dysfunction, and uterine dysfunction, which necessitated hysterectomy. These organ dysfunctions identified had a direct linkage to hemorrhage, hypertensive disease, and infection, which were leading causes of maternal deaths and MNMs in most similar studies based on clinical criteria in our environment. The different roles played by shock, cardiac arrest, gasping, cyanosis, and failure to form clots were noted. The frequency of shock was higher in women with MNMs, suggesting that a good number of them were successfully resuscitated, unlike cardiac arrest and gasping, which were associated much more with maternal deaths. This is a reflection of the deficiencies in our health facilities, where there are still yawning gaps in terms of equipment and manpower needs, especially in emergencies. ${ }^{16-19}$ 
This study stands out for being prospective and the organsystem definition of MNMs being used. It was,s however, a hospital-based study, and a wider study population may be needed for better deductions of the actual situations in the community. The pattern of the complications in the two groups were similar, as shown in Table 3, but the use of exploratory laparotomy and occurrence of severe hemorrhage were higher among women that had MNMs, and the difference was statistically significant compared to maternal death. This suggests that severe hemorrhage is one of the common complications and offers a good comparative chance for survival. ${ }^{19}$

It is thus concluded that the number of MNMs and maternal deaths that occur even in our tertiary centers is still very high. This may be due to late presentation, as unbooked emergencies in a facility that may not be optimal in terms of infrastructure, personnel, or response is thus slow and unpredictable. Despite numerous similarities, our study points out that those who succumb to death are often $<40$ years of age, poorly educated, unemployed, usually present as unbooked emergencies from a distance $>5 \mathrm{~km}$, and suffer maternal deaths within 24 hours of presentation.

\section{Disclosure}

The authors report no conflicts of interest in this work.

\section{References}

1. Say L, Souza JP; Pattinson RC for the WHO working group on maternal mortality and morbidity classification. Maternal near miss-towards a standard tool for monitoring quality of maternal health care. Best Pract Res Clin Obstet Gynaecol. 2009;23:287-296.

2. Cochet L, Pattinson RC, MacDonald AP. Severe acute maternal morbidity and maternal death audit-a rapid diagnostic tool for evaluating maternal care. S Afr Med. 2003;J,93:700-702.

3. Oladapo OT, Sule-Odu AO, Olatunji AO, Daniel OJ. "Near-miss" events and maternal deaths in Sagamu, Nigeria: a retrospectively study. Reprod Health. 2005;2:9. doi:10.1186/1742-4755-2-9

4. Ronsmans C, Filippi V. Reviewing severe maternal morbidity: learning from survivors from life-threatening complication. In Beyond the Numbers: Reviewing Deaths and Complications to Make Pregnancy Safer. Geneva: World Health Organization; 2004:103-124. Available from: https://apps.who.int/iris/bitstream/ handle $/ 10665 / 42984 / 9241591838$.pdf? sequence $=1 \&$ source $=$ post page. Accessed March 18, 2020.
5. Ibekwe PC, Dimejesi IB. Obstetric indices at the Ebonyi State Specialist Hospital Bauchi, Northern Nigeria. East Afr Med J. 2008;86(1):25-30.

6. Ozumba BC, Nwogu-Ikojo EE. Avoidable maternal mortality in Enugu, Nigeria. Public Health. 2008;122:354-360. doi:10.1016/j. puhe.2007.04.018

7. Tukur J, Jido TA, Awolaja BS. Maternal mortality in rural northern Nigeria. Trop Doct. 2008;38:35. doi:10.1258/td.2006.006356

8. Mbachu II, Ezeama C, Osuagwu K, Umeononihu OS, Obinnika C, Ezeama N. A cross sectional study of maternal near miss and mortality at a rural tertiary centre in Southern Nigeria. BMC Pregnancy Childbirth. 2017;17:251. doi: 10.11861s12884-017-1436-2

9. Oladapo OT, Adetoro OO, Ekele BA, et al; Nigeria Near-miss and Maternal Death Surveillance Network. When getting there is not enough: a nationwide cross-sectional study of 998 maternal deaths and 1451 near-misses in public tertiary hospitals in a low-income country. BJOG. 2015. doi:10.1111/1471-0528.13450

10. Tuncalp O, Hindin MJ, Sonza JP, Chou D, Say L. The prevalence of maternal near miss: a systemic review. BJOG. 2012;119:653-661. doi:10.1111/j.1471-0528.2012.03294.x

11. Maternal Health in Nigeria. A situation update; 2016 Available from: https://aphrc.org/publication/maternal-health-in-nigeria-a-situationupdate/.

12. Hil K, Thomas K, Abouzahr C, Walker N, Say L, Inoue M. Estimates of maternal mortality worldwide between 1990 and 2005:an assessment of available data. Lancet. 2007;370(9595):1311-1319. doi:10.1016/S0140-6736(07)61572-4

13. Kongnyuy EJ, van den Broek N. Audit for maternal and newborn health services in resource-poor countries. BJOG. 2009;116:7-10. doi:10.1111/j.1471-0528.2008.01994.x

14. Nelissen EJ, Mduma E, Ersdal HL, Evjen-Olsen B, van Roosmalen JJ, Stekelenburg J. Maternal near miss and mortality in a rural referral hospital in northern Tanzania: a cross-sectional study. BMC Pregnancy Childbirth. 2013;13:141. doi:10.1186/1471-239313-141

15. World Health Organization. Beyond the Numbers: Reviewing Maternal Deaths and Complications to Make Pregnancy Safer. Geneva: WHO; 2004.

16. Okusanya OB, Okogbo FO, Momoh MM, Okogbonin SA, Abebe JO; Maternal Mortality and delay. socio- demographic characteristics of maternal deaths with delay in Irrua. Niger J Med. 2007;16(1):38-41. doi:10.4314/njm.v16i1.37279

17. Mac Dorman M, Decherq E, Thoma ME. Trends in maternal by sociodemographic characteristic and cause of death in 27 states and the District of Columbia. Obstet Gynecol. 2007;129(5):811-818. doi:10.1097/AOG.0000000000001968

18. Ariyo O, Ozodregu ID, Dochi HV. The influence of the social and cultural environment on maternal mortality in Nigeria evidence from the 2013 demographic and health survey. PLoS One. 2017. 12: eo190285.

19. Ujah I, Aisien O, Mutihr J, Vanderjagt D, Glen R, Ugwu V. Factors contributing to maternal mortality in North-Central Nigeria: a seventeen year review. Afr J Reprod Health. 2005;9(3):27-40. doi: $10.2307 / 3583409$
The International Journal of Women's Health is an international, peerreviewed open-access journal publishing original research, reports, editorials, reviews and commentaries on all aspects of women's healthcare including gynecology, obstetrics, and breast cancer. The manuscript management system is completely online and includes a very quick and fair peer-review system, which is all easy to use Visit http://www.dovepress.com/testimonials.php to read real quotes from published authors. 